\title{
Aspectos morfológicos e inmunofenotípicos relevantes en rabdomiosarcoma metastásico
}

Relevant morphological and immunofenotipic aspects in metastatic rhabdomyosarcoma

\author{
- Agustín Darío Contreras Acosta', Gloria Inés Uribe1, Alexis Antonio Franco Moreno², Johnny Francisco García², \\ Edna Margarita Quintero 3 \\ 'Especialista en Hematología y Oncología Pediátrica, Fundación Hospital de la Misericordia \\ Fellow de Oncohematología Pediátrica, Universidad Nacional de Colombia \\ Especialista en Patología, Fundación Hospital de la Misericordia
}

Palabras clave: rabdomiosarcoma, leucemia mieloide aguda, metástasis en médula ósea, citometría de flujo, radioterapia, mieloblastos.

Presentamos el caso de una paciente de sexo femenino de 17 años de edad, quien ingresa a institución de cuarto nivel, centro de referencia oncológico nacional, en junio de 2014. Al ingreso refiere cuadro de un mes de evolución caracterizado por presencia de equimosis en extremidades, asociado a dolor toraco-lumbar. A ocho días previos al ingreso, presenta exacerbación de la sintomatología descrita, por lo cual consulta al servicio de urgencias del sitio de remisión. Allí toman laboratorios documentando hemograma con trombocitopenia, sospechando inicialmente cuadro de púrpura trombocitopénica inmune (PTI). Inician manejo con pulsos de esteroide sin mejoría clínica ni paraclínica, por lo que remiten a institución de mayor complejidad. Durante su estancia en centro de atención inicial, realizan imágenes diagnósticas (TAC toracolumbar) que reportan masa retrocrural probablemente de origen ganglionar desde el tercio distal del esófago hasta nivel renal, con derrame pleural derecho asociado.

Al examen físico de ingreso en institución de cuarto nivel, paciente en regulares condiciones generales. Peso: $52 \mathrm{~kg}$, talla: $151 \mathrm{~cm}$, IMC: 22,8, DS: 0,61 . Signos vitales: FR $20 \times \mathrm{mn}, \mathrm{FC} 90 \times \mathrm{mn}$. Palidez mucocutánea moderada, hidratada y sin signos de dificultad respiratoria. Sin adenopatías. Disminución del murmullo vesicular a nivel basal izquierda. Sin hepatomegalia ni esplenomegalia. Equimosis en extremidades. Sin otros hallazgos de importancia al examen físico.

Laboratorios iniciales: cuadro hemático con leucocitos: $12.110 \mathrm{k} / \mathrm{l}$, neutrófilos: 6.750 , linfocitos: 3.760, hemoglobina: $8,9 \mathrm{~g} / \mathrm{dl}$, hematocrito: $27 \%$, VCM: 84,4, plaquetas: $240 \times 109 / 1$. Extendido de sangre periférica: formas inmaduras, blastos del $3 \%$, metamielocitos, promielocitos, mielocitos. LDH: $1.620 \mathrm{U} / \mathrm{l}$, con electrolitos, función renal, hepática y tiempos de coagulación normales. El TAC toracolumbar evidencia masa retrocrural que se extiende desde el tercio distal del esófago hasta nivel renal. Se hace una impresión diagnóstica inicial de leucemia mieloide aguda (sarcoma granulocítico) y en el mielograma (ver figura 1) infiltrado por blastos de aspecto mieloide. Se efectúa citometría de flujo multiparámetro de médula ósea con panel de anticuerpos ALOT (metodología Euroflow), sin alteraciones fenotípicas ni presencia de blastos. En junta de oncología, se considera por localización anatómica de la masa tumoral un tumor neuroectodérmico primitivo versus rabdomiosarcoma. Se inicia 


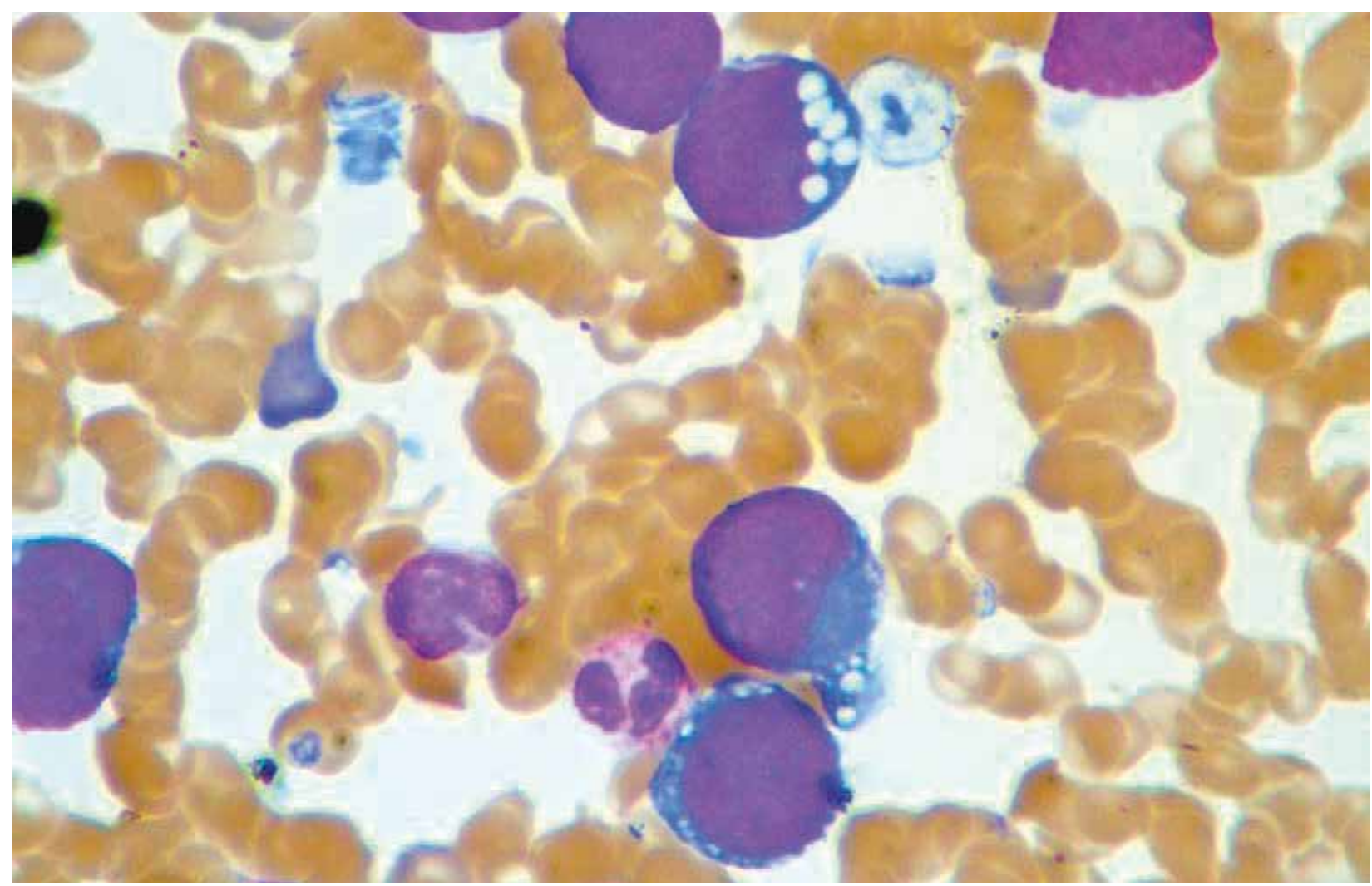

Figura 1. Mielograma con tinción de Wright. Se observan células de aspecto inmaduro, abundante citoplasma, vacuolados, sugestivos de blastos mieloides monocitoides. Imagen 100x.

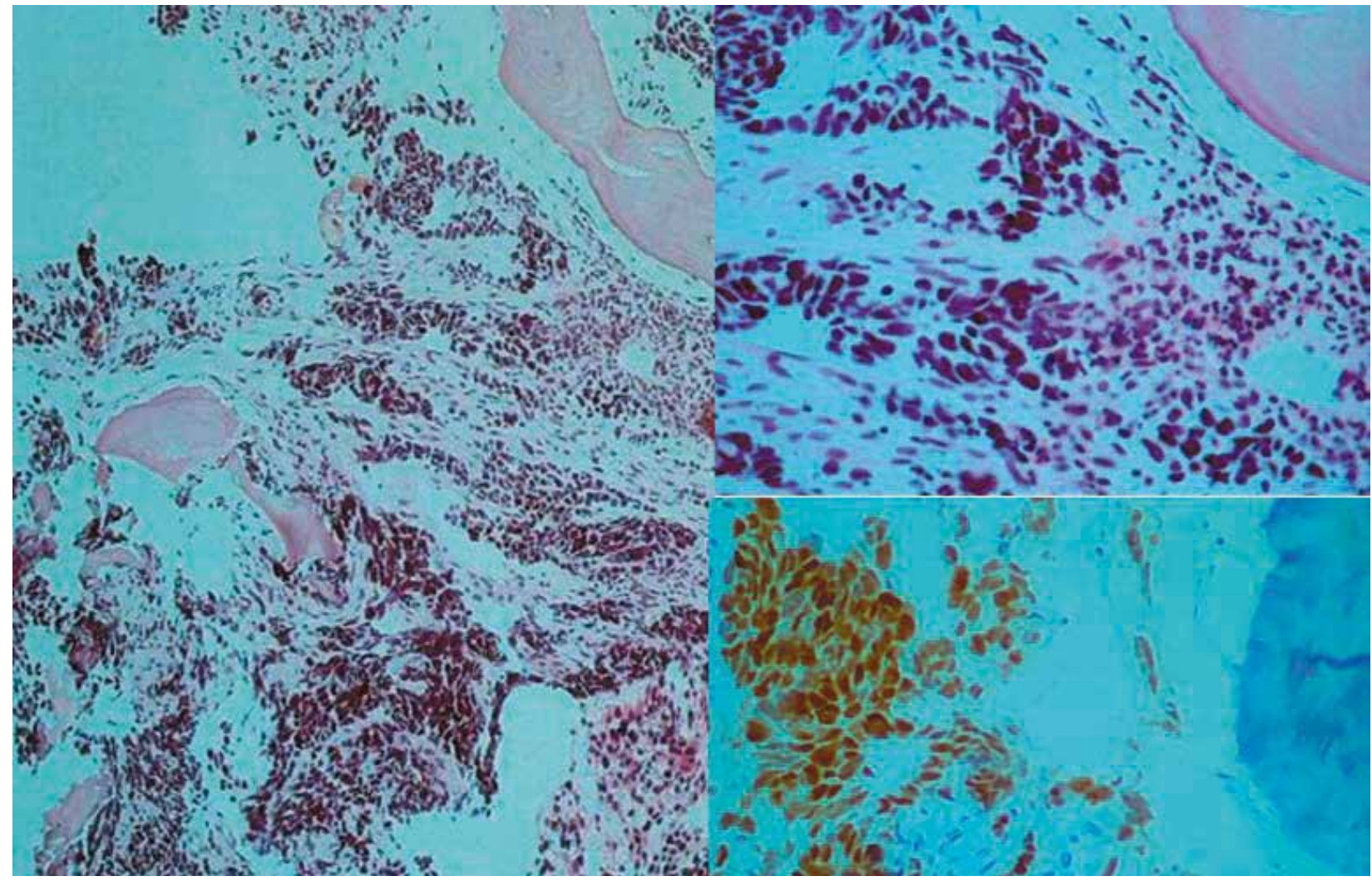

Figura 2. Médula ósea. H\&E 10x. a) Infiltración por tumor embrionario. b) H\&E 40x. Células embrionarias. c) Mif4. Positividad en rabdomioblastos. 
citorreducción con vincristina, ciclofosfamida y actinomicina. El reporte definitivo de patología informa infiltración de médula ósea por rabdomiosarcoma (ver figura 2). Se hace estadificación con TAC de tórax, abdomen y gammagrafía ósea, considerando estadio IV. Se inicia protocolo de quimioterapia para manejo de rabdomiosarcoma con esquema VAC. Recibe además manejo con radioterapia técnica IMRT 30 sesiones (5.050 cGy dosis total). Presenta, durante protocolo de quimioterapia clínica, neuropatía periférica, confirmada por estudios de neuroconducción (polineuropatía motora y sensitiva). Termina protocolo de quimioterapia en agosto de 2015. Completó radioterapia a retroperitoneo con técnica IMRT hasta 5.040 cGy. En imágenes control de fin de tratamiento, se observa gran masa sólida de aspecto tumoral probablemente metastásica, que realza con el medio de contraste, compromete la pared torácica en su aspecto posterior izquierdo y el canal intrarraquídeo, a la altura de T5. El componente intrarraquídeo tiene una longitud de $5,2 \mathrm{~cm}$ (se extiende a nivel de tres cuerpos vertebrales de T4 a T6), ocupa el canal en más de un $60 \%$ y desplaza la médula espinal hacia anterior y a la derecha. No hay compromiso de las costillas adyacentes, ni de la región extrapleural de la pared torácica. Se considera paciente con patología tumoral altamente agresiva, sin remisión de la enfermedad. Se indica radioterapia paliativa.

\section{Discusión}

El rabdomiosarcoma es el sarcoma de tejidos blandos más frecuente en la población infantil'. Constituye aproximadamente el 3,5\% de los casos de cáncer entre los niños de 0 a 14 años y el $2 \%$ de los casos entre los adolescentes y los adultos jóvenes de 15 a 19 años de edad². Usualmente se manifiesta como un tumor primario en cabeza o cuello y, en ocasiones, se acompaña de infiltración metastásica al momento del diagnóstico ${ }^{3}$. Alrededor de un $20 \%$ de los pacientes diagnosticados de novo tendrán metástasis a distancia en una o más localizaciones, siendo la más habitual el pulmón, entre el $40 \%$ al $50 \%$; la médula ósea, entre el $20 \%$ al $30 \%$; y el hueso, del 10 al $15 \%{ }^{4-6}$. En estos casos, cuando el análisis parte de la localización metastásica, es difícil generar un diagnóstico preciso, puesto que, en ocasiones, cuando las células tumorales llegan a la médula ósea, pueden confundirse con blastos leucémicos, particularmente de origen mieloide y con predominio de diferenciación megacariocítica ${ }^{7,8}$. Esto debido a que, en el aspirado de médula ósea, pueden aparecer un infiltrado difuso de células blásticas con citoplasma agranular moderado, núcleos redondos y grandes, y nucléolos prominentes con vacuolas que se pueden confundir con una neoplasia hematolinfoide ${ }^{7-9}$. Lo anterior no solo ocurre con los procesos metastásicos en médula ósea de los rabdomiosarcomas, sino también en otras neoplasias, como el neuroblastoma, el sarcoma de Ewing, el tumor neuroectodérmico y el tumor de Wilms ${ }^{10}$. Por esta razón su diferenciación es importante, debido a que el pronóstico y el tratamiento difieren uno de otro $y$, aunque se han documentado pocos casos de rabdomiosarcoma metastásico a médula ósea ${ }^{9-11}$, la literatura reporta algunos en los que se han realizado tratamientos erróneos enfocados en leucemias linfoides agudas $^{9-12}$. Por eso, la utilización de marcadores inmunohistoquímicos, el análisis citogenético y, ocasionalmente, la microscopia electrónica permitirá en la mayoría de los casos obtener un diagnóstico definitivo, para así establecer el mejor protocolo terapéutico.

\section{Referencias}

1. Weiss SW, Goldblum JR. Rhabdomyosarcoma. En: Weiss SW, Goldblum JR, editors. Enzinger and Weiss's soft tissue tumors. $5^{\text {th }}$ ed. China: Elsevier; 2008. p. 595-632.

2. Pizzo PA, Poplack DG. Principles and practices pediatric oncology. $5^{a}$ ed. Filadelfia: Lippincott; 2005.

3. Wang $C$. Childhood rhabdomyosarcoma: recent advances and prospective views. J Dent Res 2012;91(4):341-50.

4. Khanna DM, Belurkar S, Manohar C, Ray S, Srilatha P, Suvarna N. Rhabdomyosarcoma with bone marrow infiltration: a diagnostic dilemma. The Internet Journal of Oncology 2012;8(2).

5. Weiss AR, Lyden ER, Anderson JR, Hawkins DS, Spunt SL, Walterhouse DO, et al. Histologic and clinical characteristics can guide staging evaluations for children and adolescents with rhadomyosarcoma: a report from the Children's Oncology Group Soft Tissue Sarcoma Committee. J Clin Oncol 2013;31(26):3226-32.

6. Breneman JC, Lyden E, Pappo AS, Link MP, Anderson JR, Parham DM, et al. Prognostic factors and clinical outcomes in children and adolescents with metastatic rhabdomyosarcoma: a report from the Intergroup Rhabdomyosarcoma Study IV. J Clin Oncol 2003;21(1):78-84 
7. Shinkoda $Y$, Nagatoshi $Y$, Fukano R. Rhabdomyosarcoma masquerading as acute leukemia. Pediatr Blood Cancer 2009;52(2):286-7.

8. Srinivas U, Pillai L, Kar R, Mahapatra M, Gujra S, Pati HP. A case of rhabdomyosarcoma masquerading as acute leukemia at presentation: a case report. Indian J Pathol Microbiol 2007;50(4):917-9.

9. Ortuño FJ, López-Poveda MJ. Rhabdomyosarcoma presenting with leukemic phase and massive bone marrow infiltration. Blood 2016;127(26):3458.
10. Aida $Y$, Ueki T, Kirihara $T$, Takeda $W$, Kurihara $T$, Sato $K$, et al. Bone marrow metastasis of rhabdomyosarcoma mimicking acute leukemia: a case report and review of the literature. Intern Med 2015;54(6):643-50.

11. Jelić-Puskarić B, Rajković-Molek K, Raić L, Batinić $D$, Konja J, Kardum-Skelin I. Rhabdomyosarcoma with bone marrow infiltration mimicking hematologic neoplasia. Coll Antropol 2010;34(2):635-9 